\title{
VIRTUAL SIMULATION OF ROPS ON THE CABIN STRUCTURE
}

\author{
Rajesab Diddimni $^{1}$, Ravichandra Doddamani ${ }^{2}$, S.N.Kurbet ${ }^{3}$ \\ ${ }^{I}$ PG Student (Machine design), Department of Mechanical Engineering, BEC Bagalkot, Karnataka, India \\ rajudiddimani@gmail.com \\ ${ }^{2} P G$ Student (Machine design), Department of Mechanical Engineering, BEC Bagalkot, Karnataka, India \\ ravi.mdoddamani@gmail.com \\ ${ }^{3}$ HOD Department of Mechanical Engineering, BEC, Bagalkot. Karnataka, India \\ kurbetsn@rediffmail.com
}

\begin{abstract}
Rollover protective structure is an additional safety structure provided to safe guard the driverloccupant operating the heavy machinery, which are basically used in the mining, forests, material handling, agriculture and rural areas operation in non uniform surface, large weight and high center of gravity make this susceptible to dynamic stability. The risk for rollover of earth movers are being increased day by day. Under these conditions the rollover protective system is to protect the occupant and driver. The model of ROPS is created by using CAD software. Meshing is created by using HYPERMESH software. FEA analysis of ROPS is carried by using the ABAQUS software. This paper deals with the energy absorbed by the ROPS during the rollover of a vehicle in different Loading conditions and Deflection of ROPs well within the safe limit accordance to the ISO 3471:2008.
\end{abstract}

Keywords: ROPS, FEA, Cabin, CAD.

\section{INTRODUCTION}

Heavy mobile machinery likes earth movers are used from many years in big industrial projects around the world. ROPS are widely used in material handling, rural and mining areas operation in non uniform surface, large weight and high center of gravity make this affected to dynamic stability. The difficulty for rollover of earth movers increases, while working on slopes and non uniform land. In many conditions earth movers and loader are loaded in a manually and loading extend beyond their designed limits under these conditions vehicles rollover, which cause to many injuries and accidents to driver. In order to avoid from these accidents heavy machinery are provide the protective structure which is provide the safe zone under the rollover for a cabin structure and driver such Rollover protective structure (ROPS) minimizes the accidents.

Rollover is a serious problem facing our society worldwide. According to NIOSH (National Institute for occupational safety and Health).There are nearly 250 tractor rollover accidents per year. Rollovers are the major cause for serious spinal injuries resulting paralysis. The world's best mining resource companies are identified rollover crashes as a serious safety risk for their workers and vehicles. These companies are know, there is no qualified and effective vehicle design requirement for a ROPS. According to ISO 3471 different ROPS design are available depending upon their specifications and applications, these are used in the vehicle manufacturing to protect the driver during the rollover.

\section{LITERATURE SURVEY}

Sandeep (2015) studied the experimental \& analytical investigation of two post foldable ROPS of agriculture tractor they observed that the modification of the existing design \& proper selection of material sustained more energy absorbing capacity at the hinges. The newly designed material seems to withstand the rollover condition making more safety aspect for the occupant. Hence, can be utilized the existing design making it more reliable in terms of safety standard. Amandeep Singh (2012) studied Rollover Protective Structure provide safe zone for driver. Such Rollover Protective Structure is expected to meet minimum perform criteria to secure driver safety for a closed cabin for structural rigidity and safety.

\section{METHODOLOGY}

The CAD modeling is generated by using the CATIA V5 tool. Then CAD model is converting into .step/iges. The iges file is imported into HYPERMESH 12, after importing the file the geometry clean up is carried out. Once the geometry imported into HYPERMESH, the midsurface are extracted. Shell element carried out on the mid surface Then discretization the model into small elements using the mesh command.

a. Boundary Conditions:

The bottom surface of the cabin structure is fixed to vehicle base with help of bolts. 


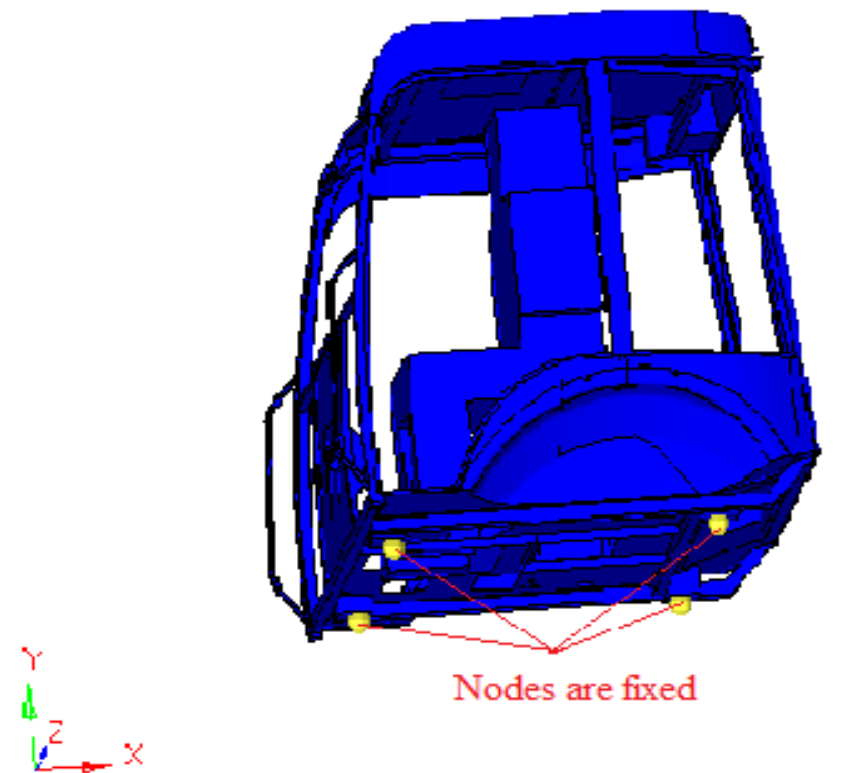

Fig.1. Boundary condition to the cabin structure

$b$. Loading Conditions: during the rollover of vehicle, the cabin structure of a vehicle is subjected to lateral loading, vertical loading and longitudinal loading as per ISO 3471.Accordingly boundary conditions are applied to the model.

Table 1. Loading conditions

\begin{tabular}{|l|l|}
\hline \multicolumn{2}{|c|}{ LOADING CASES } \\
\hline Loading case 1 & Lateral Loading \\
\hline Loading case 2 & Vertical Loading \\
\hline Loading case 3 & Longitudinal Loading \\
\hline
\end{tabular}



Fig.2. Loading condition to the cabin structure

c. Analysis

The CAD model is built as per the requirements. And further the model is meshed with HYPERMESH 12.0 software boundary and loading conditions are applied. The meshed model is then analyzed with ABAQUS software for the purpose of different conditions like Lateral loading, vertical loading and longitudinal loading

\section{RESULTS AND DISCUSSIONS}

The virtual simulation of ROPS on cabin structure done by using FEA software. Under different loading condition like Lateral loading, vertical loading and longitudinal loading. During the rollover of the vehicle first vehicle subjected to the lateral loading. This loading is dangerous to the vehicle because very large forces applied on the sides of the post. After applying lateral loading to vehicle, the vehicle is subjected to vertical loading on top of the cabin. It is the second phase of the rollover. In third phase the vehicle is subjected to the longitudinal loading. For these loading conditions we have to check the Von Mises stress, Max principal stress, Plastic strain, Displacements and Energy absorbed by the ROPS during the rollover of the vehicle

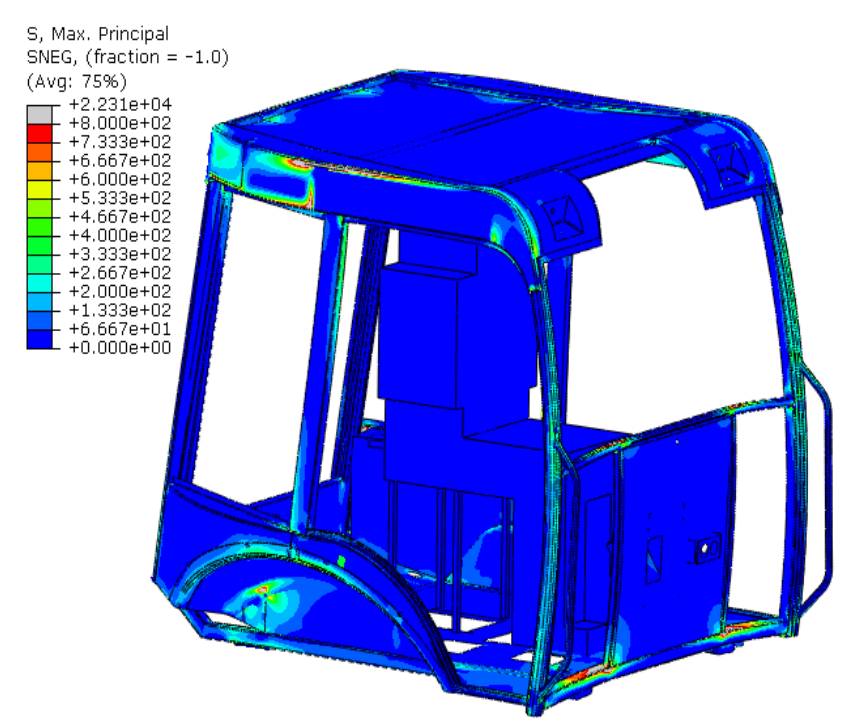

Fig.3. Max principle stress

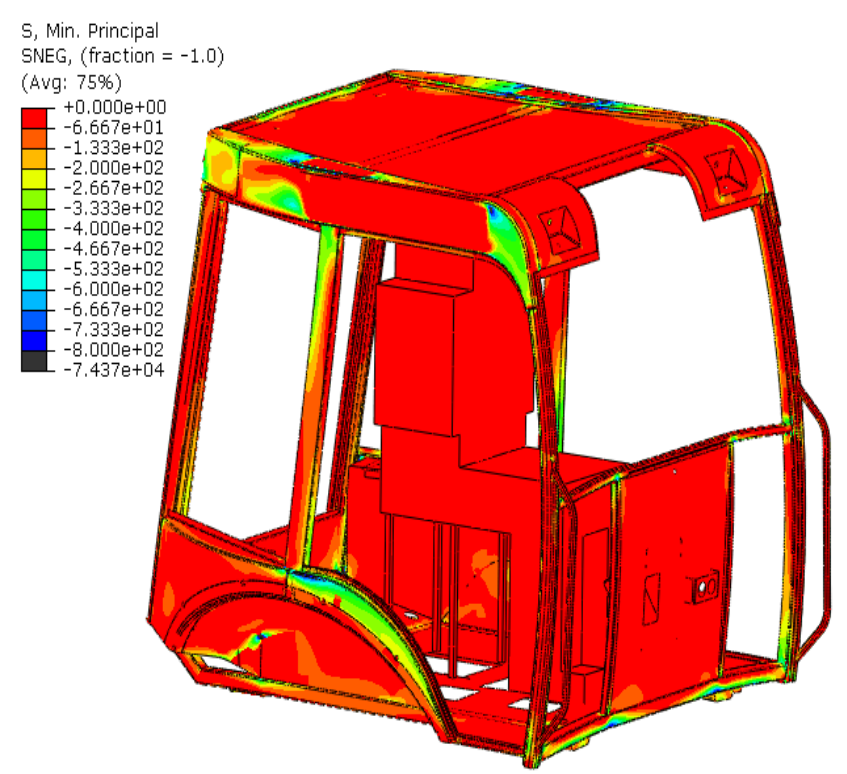

Fig.4. Min. Principal stress 
The above figure 3 and 4 show the maximum principal and minimum principal stress of ROPS on the cabin structure. And these stresses are well within the limit.

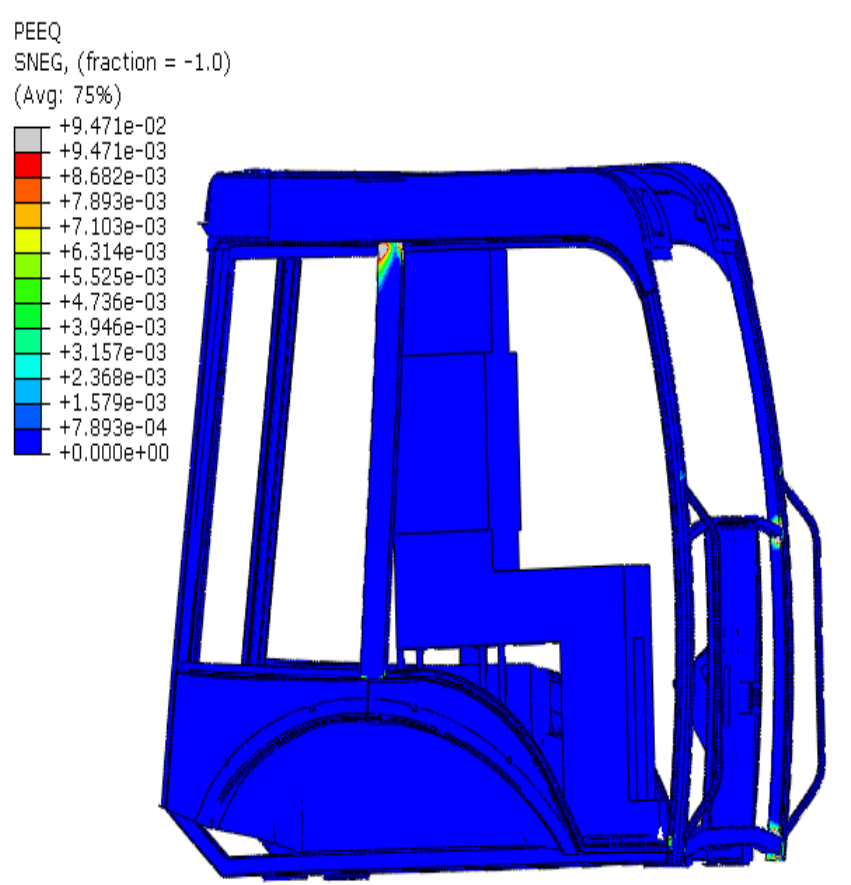

Fig.5. plastic strain

The above figure 5 show the Plastic strain in the ROPS during the rollover of the cabin

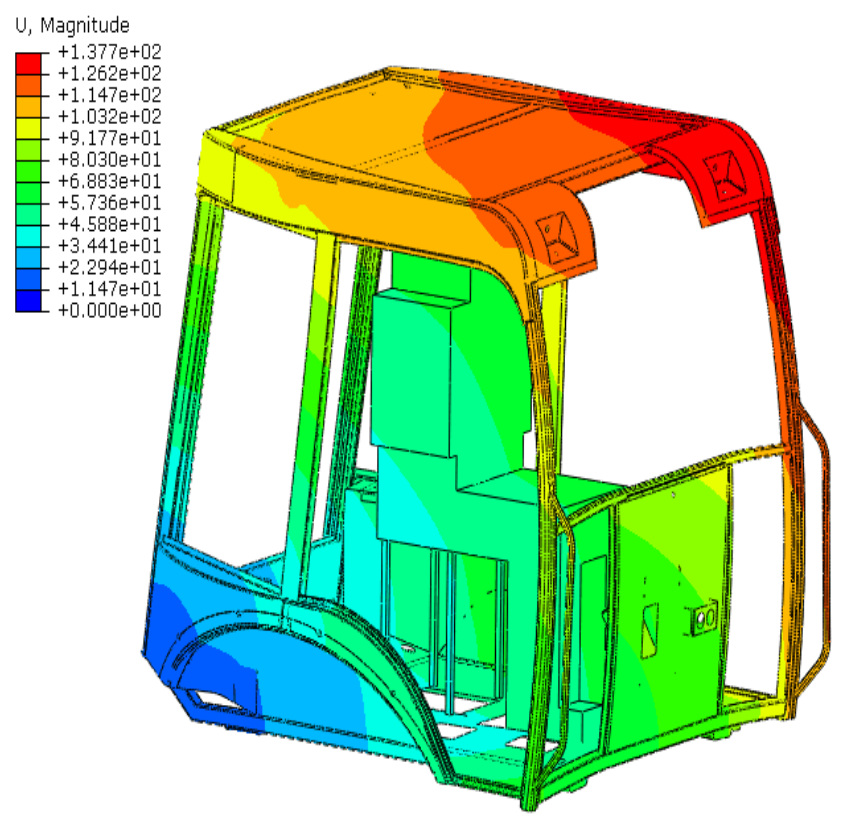

Fig.6. Displacement magnitude

The above figure 6 shows the displacement magnitude of ROPS during the rollover of the cabin.

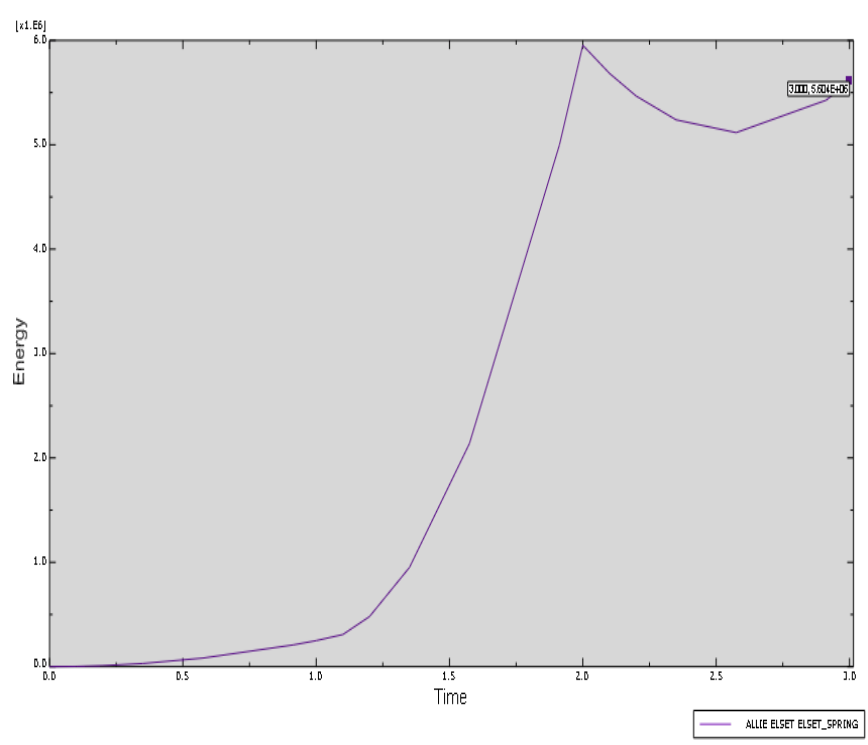

Fig.7. Energy absorbed by the ROPS

The above graph shows the Energy absorbed by the ROPS, during rollover of a vehicle. The maximum energy absorbed by the ROPS is $5.6 \mathrm{E}^{05} \mathrm{MPa}$.

\section{CONCLUSION}

With the reference of above figures and graphs of rollover cabin structure, we conclude that the energy absorbed by the ROPS during the rollover of a vehicle in different. Loading conditions and Deflection of ROPs are well within the safe limit accordance to the ISO 3471:2008.

\section{REFERENCES}

[1] BJ Clark, DP Thambiratnam "Analytical and experimental investigation of the behavior of the rollover protective structure" (2006) 84(1):pp. 29-34.

[2] Sandeep R. Sonawane, Vijay K. Kurkut experimental and analytical investigation of rollover protection structure for agricultural wheeled tractor (10): October, 2015] ISSN: 2277-9655.

[3] Amandeep Singh, Vinod K. Banthia, Monish Gowda. "Numerical Evaluation of a Closed Cabin of Earthmovers for Structural Rigidity and Safety. Volume 11, issue1, April 2012 49-55

[4] DP Thambiratnam, BJ Clark and NJ Perera "Performance of a Roll over Protective Structure for a Bulldozer" Journal of Engineering Mechanics. 135(1). pp. 31-40.

[5] Dylan J Agius, Kyriakos I Kourousis, Monir Takla and Aleksandar Subic "'Enhanced Nonlinear Material Modeling for the Analysis and Qualification of Rollover Protective Structures (ROPS)" 2 January 2016.

[6] Syed Khaiser, kiran narkar, D Panchangad. "Optimization of rollover protective structure" Vol. 2, Issue 04, 2014 | ISSN (online): 2321-0613.

[7] Cobb, L.J. "ROPS Force and Energy Absorption from Simulated Overturn Analysis", SAE Paper 760691, 1976 